\title{
HVEM of Gromia (Protista) from the Abyss
}

\author{
S.S. Bowser,* A.J. Gooday,** J. Fahrni, $* * *$ and J. Pawlowski*** \\ * Wadsworth Center, N.Y. State Department of Health, P.O. Box 509, Albany, NY 12201-0509 \\ ** National Oceanography Centre, Southampton, SO14 3ZH, UK \\ *** Department of Zoology and Animal Biology, University of Geneva, Geneva, CH
}

Gromia is a genus of large $(0.3 \mathrm{~mm}-5 \mathrm{~cm}$ diameter $)$, benthic protists belonging to the supergroup Rhizaria. Frequently overlooked as "invertebrate eggs" or "species incertus" in biodiversity surveys, protistologists characterize Gromia by the presence of an organic shell with one or more apertures through which branching pseudopodia are extended. These organisms are abundant in certain marine settings; e.g., in eastern McMurdo Sound, Antarctica, populations may exceed 80,000/ $\mathrm{m}^{2}$ [1]. Recent molecular studies, and deep-sea sampling, show that their diversity is much greater than previously estimated.

Although Gromia is now known to be an abundant and highly diverse group [1-4], the role of these organisms in marine ecosystems remains poorly defined. One factor confounding biological studies of Gromia is the presence of numerous accretions of mineral grains, termed stercomata, within its cytoplasm. Stercomata and surface-bound debris render the sectioning of conventional silver/gold sections for EM nearly impossible. To define structural characters useful for species identification, we overcome this limitation by cutting thick $(>1-\mu \mathrm{m})$ sections using relatively inexpensive "histology grade" diamond knives and view them at $1 \mathrm{MeV}$ using the Albany HVEM [e.g., 1,4].

In the present study, an unusually large Gromia-like organism (Fig. 1) was collected from abyssal stations off the eastern margin of South America during the DIVA 3 expedition (July - August, 2009) aboard RV METEOR. By SEM (Fig. 2), the surface of these organisms appeared vested by a finely agglutinated layer that masks the presence of diagnostic pores in the shell [1-5].

Characteristic stercomata were seen by LM (Fig. 3) and HVEM (Fig. 4) of thick sections. The shell wall was found to be perforated by pores that follow tortuous paths through the thickened fibrous interior regions, and terminate in stacks of "honeycomb" structures (Fig. 5) that are unique to Gromia. Oriented normal to the beam, these structures appeared as electron-opaque bands that correspond to the Type I patterns seen in Gromia oviformis [5]. These findings establish the deepest record of Gromia, and extend its range to the abyssal South Atlantic [6].

\section{References}

[1] S.S. Bowser et al., Antarctic J. USA 31 (1996) 122.

[2] N. Rothe et al., Zool. J. Linnean Soc. 157 (2009) 451.

[3] A. da Silva et al., Marine Biol. 148 (2006) 769.

[4] A.J. Gooday et al., Deep-Sea Res. II 47 (2000) 55.

[5] R.H. Hedley and J.S. Wakefield, Bull. Brit. Mus. Nat. Hist. 18 (1969) 69.

[6] Microscopy supported in part by NSF grant ANT-0739583. 

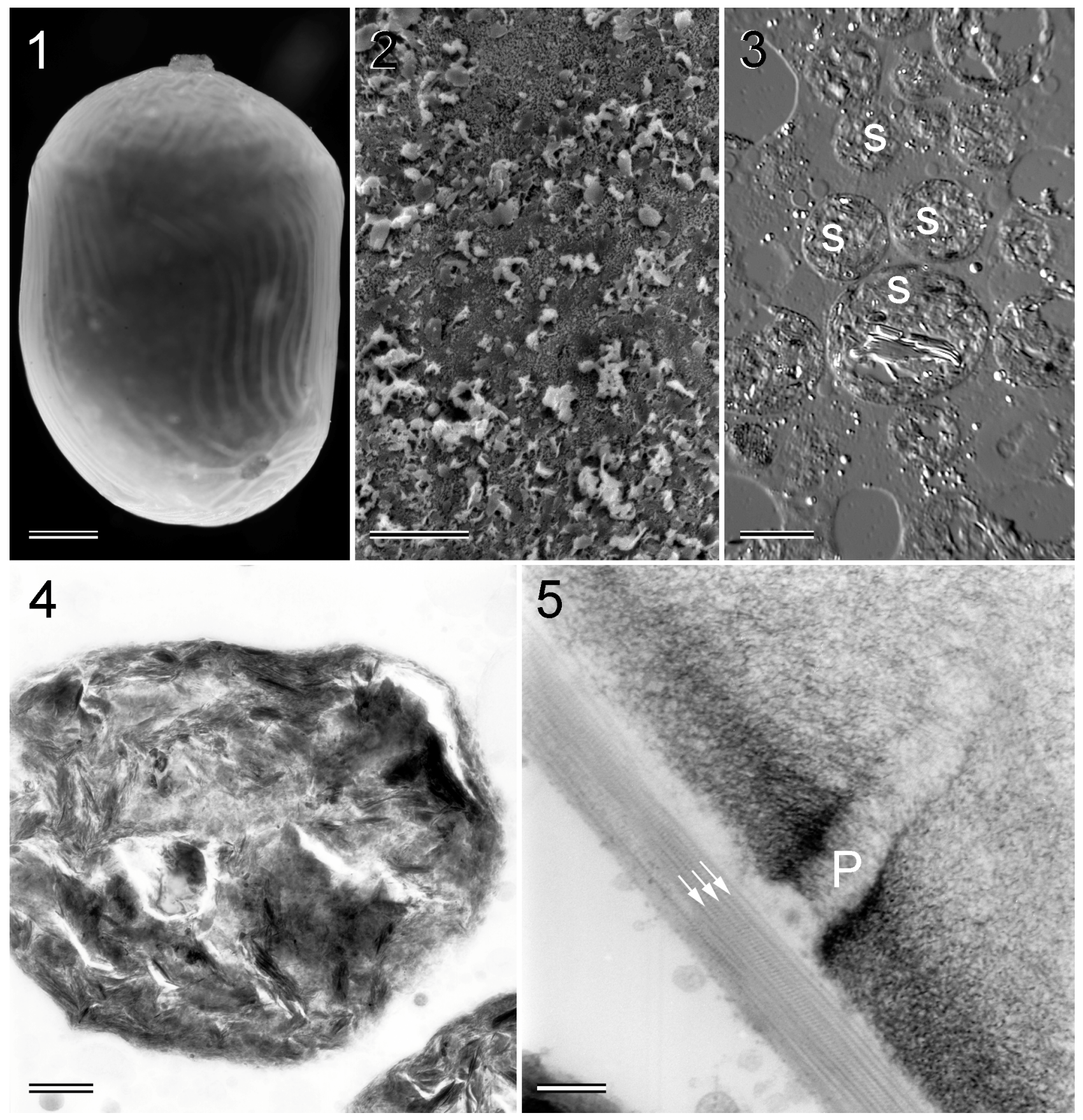

Fig. 1. Reflected light micrograph of Gromia sp. from SW Atlantic. Oral apparatus (aperture) oriented toward top. Folds in flexible wall give rise to banded appearance. Bar $=500 \mu \mathrm{m}$.

Fig. 2. SEM view of shell surface. Note finely agglutinated material. Bar $=2 \mu \mathrm{m}$.

Fig. 3. Differential interference contrast micrograph of thick section through cytoplasm. Note numerous stercomata $(\mathrm{S})$. Bar $=10 \mu \mathrm{m}$.

Fig. 4. Stercomata, as seen by HVEM, are mineral conglomerates. Bar $=1 \mu \mathrm{m}$.

Fig. 5. HVEM of pore (P) terminating near stacked honeycomb structures (arrows). Bar $=0.25 \mu \mathrm{m}$. 